\title{
Exquisite Attention: Introduction to the Special Issue of Language \& Literacy
}

It gives me great honour to welcome you to this special issue of Language \& Literacy. In this issue you will find a range of thoughtful and provocative inquiries that reflect some of the diverse range of research in language and literacy education today. This issue was born of the recent marriage of the Language and Literacy Researchers of Canada (LLRC) and Language \& Literacy: A Canadian ejournal. From this point forward these two organizations have made a commitment to support each other in their efforts to sustain critical conversations about language and literacy education and research.

Submissions for this issue were solicited from delegates to the Language and Literacy Researchers of Canada Pre-Conference, held at Carlton University in Ottawa on May 22, 2009. At this pre-conference, the LLRC organizers (Jeffrey Wood, Suzanne Smythe, Tara Lynn Scheffel and myself) chose to dramatically change the format of their meeting. Rather than give a traditional 15 minute presentation, delegates were asked to participate in day long, small group discussions about their own work and the work of their group members. This shift in format was suggested by various members of LLRC, as some members had experienced this kind of "exquisite attention" at other conferences.

When it was suggested, the idea was warmly welcomed, as many of us felt we could benefit more from such sustained conversations, than we could from presenting our work in a traditional "stand up, sit down" way.

In organizing the pre-conference, we were delighted that Dr. Suzanne De Castell (Simon Fraser University) accepted our invitation to present a keynote for the day. Dr. Castell has kindly provided the text of that keynote as the opening piece for this special issue. In her keynote, Dr. De Castell spoke specifically to the idea of "attention" and "attentional economies", provoking us to think carefully about what we pay attention to and what counts as "paying attention". She reminds us that what is sometimes called "paying attention" in classrooms around the world, is really little more than compliance and "performing attentional behaviours". Unfortunately, because we can't actually know when people are truly "paying attention" and yet we think we should be monitoring such things, as educators, we often fall into accepting these behaviours as if they were truly significant or reflected our students' capabilities as learners.

Dr. De Castell then shared with us some of the work that she has been doing using a multimodal analysis program (MAP) to examine educational interactions. This tool allows for the coding and analysis of verbal and non-verbal communication. As Dr. De Castell suggests, when used with a selection of audio-visual data, this tool allows researchers to attend to a range of communicative modes and to how these modes "interplay, converge and are coordinated over time". Given the recent increase in generating multimodal data in language and literacy education research, this tool may become particularly useful for researchers in our field.

The second article in our special issue, What is lost and what remains: an exploration of the pedagogical challenges of online discussions in two online teacher education 
learning communities comes to us from Karen Armstrong (York University) and Margaret Mason (York University), two language and literacy educators who are pioneers in designing and teaching online literacy education courses. While a great many articles have outlined the educational benefits of online communication, and while an increasing number of faculties of education have been making use of online courses in their work with teacher candidates, Armstrong and Mason provide a clear illustration of some of the challenges that come with creating rich learning environments in these contexts. In particular, they focus on the need to create feelings of safety and trust, and how they provide their students with a sense of control and choice in their online learning communities. Armstrong and Mason do a remarkable job outlining for us the kinds of questions course designers need to be aware of as they create online courses and course components.

In our third article, Complex language encounters: Observations from linguistically diverse South African classrooms, Rinelle Evans (University of Pretoria) and Ailie Cleghorn (Concordia University) examine some of the linguistic and cultural landscapes of urban classrooms in South Africa. Their portrait of "complex language encounters" reminds us of how quickly language-in-education teaching and research can become outdated and irrelevant if they do not keep pace with changing political, linguistic and demographic tides. As they outline in their study, the majority of the teachers and students they observed worked in English, regardless of the fact that neither group used this language outside school. As Evans and Cleghorn make clear, the quality of the language of instruction in these classrooms raises serious questions about these children's access to meaningful learning, higher education and global citizenship. Evans and Cleghorn assert a number of recommendations for teacher educators and policy makers. It can be hoped that their recommendations are heard.

Our fourth article is a different kind of exploration entirely. In The Interpretive Movements of Language and Desire: Engagements of Poetry and Place in Qualitative Research, David Lewkowich (McGill) explores "the impressions and effects of a researcher's desires" providing a "haunted analysis of autobiographical place". As he writes, the result "is a methodological inquiry into the ways we move when we do educational re-search, and the curricular paths that languages help to inscribe in this performance". He reminds us of the importance of places and spaces in our work.

Our closing article, Intersections between and understandings of literacy and disability in a B.Ed program: Discourses, tensions and curriculum comes to us from Luigi Iannacci (Trent University) and Bente Graham (Trent University). Iannacci and Graham investigated teacher candidates' initial understandings of literacy and learning disabilities and their subsequent understandings after 1) taking literacy courses grounded in sociocultural and critical disability theory, and 2) participating in a tutoring program with students identified as learning disabled or having "special needs". Iannacci and Graham found that the students' understandings of literacy appeared to shift somewhat following these experiences, but that their understandings of learning disabilities did not appear to shift in the same way. Iannacci and Graham suggest this difference can be attributed, in part, to the dominance of limited ideas of learning disabilities in institutional discourse and official government documents. In addition, they reflect on how one of their own 
classroom assignments may have replicated dominant discourses rather than challenged them. This kind of reflective research is useful for all of us as we try to create a continual feedback loop between our teaching and our theoretical orientations.

Creating this special issue has been an immensely enriching experience for me as a guest editor.

I am hugely grateful to the authors who submitted to this special issue.

Thank you for sharing your work with us and engaging in sustained conversations about language and literacy education.

Thank you as well to the regular editorial board who were extremely supportive and kind in mentoring me through this issue. Without their wisdom and generosity, this issue would not exist. An enormous thank you to the anonymous reviewers who set aside time to read all of the submissions so carefully and who provided such exquisite attention to our authors. May you all experience the pleasure of being listened to closely and considered with care.

\section{Author Biography}

After completing her doctorate in Language and Literacy Education at the University of British Columbia, Lyndsay Moffatt held a two year SSHRC post-doctoral fellowship at Simon Fraser University. She is currently an Assistant Professor of Elementary Language and Literacy Education at Lakehead University. Her research interests include critical approaches to literacy education, discourse analysis and examining research data as social interaction. 